\title{
Comparative Reliability of the Infant Motor Profile (IMP) in the Greek Language for Infants 3 to 18 Months
}

\author{
Thomas Besios' ${ }^{1}$ Alexandra Hristara-Papadopoulou', Paris Iakovidis', \\ Savas Mauromoustakos ${ }^{1}$, Yannis Tzioumakis ${ }^{2}$, Olympia Vliagofti ${ }^{1}$, Nikos Comoutos ${ }^{2}$ \\ ${ }^{1}$ Pediatric Physiotherapist, Department of Physical Therapy, Alexandrio University of Thessaloniki, Thessaloniki, Greece \\ ${ }^{2}$ Department of Physical Education and Sport Science, University of Thessaly, Thessaly, Greece \\ Email: tombesios@yahoo.gr
}

How to cite this paper: Besios, T., Hristara-Papadopoulou, A., Iakovidis, P., Mauromoustakos, S., Tzioumakis, Y., Vliagofti, O. and Comoutos, N. (2018) Comparative Reliability of the Infant Motor Profile (IMP) in the Greek Language for Infants 3 to 18 Months. Open Journal of Pediatrics, 8, 1-7.

https://doi.org/10.4236/ojped.2018.81001

Received: December 22, 2017

Accepted: February 24, 2018

Published: February 27, 2018

Copyright $\odot 2018$ by authors and Scientific Research Publishing Inc. This work is licensed under the Creative Commons Attribution International License (CC BY 4.0).

http://creativecommons.org/licenses/by/4.0/

\begin{abstract}
In recent years, many tests have been developed to evaluate the mobility and functional capacity of children with Cerebral Palsy (CP). The Infant Motor Profile (IMP) is a recent qualitative infant kinetic behavior assessment for ages 3 to 18 months. Thus, the purpose of the present study is to determine the reliability of the IMP translated for the first time for Greek population, for infants aged 3 to 18 months in order to provide a reliable tool in the hands of experts. Twenty infants ( 11 girls and 9 boys) with average age \pm 12.75 months participated in the study. The Greek version of the IMP and a Nikon 5300 digital camera for video recording were used for data collection. The results showed that there were no statistically significant differences between the two independent evaluators and that the Greek IMP had strong reliability. Overall, the results of the present investigation provided considerable evidence suggesting that the Greek version of the IMP test is reliable and can be used to detect kinetic disorders in infants aged 3 to 18 months for the Greek population.
\end{abstract}

\section{Keywords}

IMP, Test, Infants, Assessment, Reliability

\section{Introduction}

Over the last 3 decades, perinatal care advancement and further development of neonatal intensive care units have led to increased premature infant survival rate, particularly in low birth weight premature infants $(\mathrm{LBW})(\mathrm{BW}<1.500 \mathrm{~g})$ and in extremely low birth weight infants (ELBW) $(\mathrm{BW}<1.000 \mathrm{~g})$, [1] (Hers- 
kindi, Greisen \& Nielsen, 2015). Each premature infant that is released from the medical unit, will be in need of further close monitoring. Follow-up is a systematic monitoring by a team of specialized medical stuff, which includes a pediatrician, a pediatrician specialized in development, and a specialized physiotherapist as well as other specialized perinatal scientists. Perinatal complications include cerebral palsy, sensory and motor deficits, learning and behavior disorders, and respiratory problems. Low gestational age and birth weight of the premature infant are related with higher risk of serious neurodevelopmental disorders. Moreover, in premature infants with Intrauterine Growth Restriction (IUGR), neurodevelopmental disorders are more frequent and severe compared to premature infants with normal weight [2] (Schlapbach et al., 2011).

Cerebral Palsy (CP) is a group of permanent cerebral disorders, which are attributed to lesions or abnormal cerebral development during prenatal or perinatal stage. Symptoms include poor motor control, muscle stiffness and in some cases, skeletal deformations [3] (Koman, Smith, \& Shilt, 2004). Various studies have shown that higher rates of CP are related with short gestational length and birth weight $(<1500 \mathrm{~g})$, as well as with twin births with a rate of 9.7 in 1000 births [4] (Liu et al., 2000). For the evaluation of the mobility and functional capacity of infants with $\mathrm{CP}$, several tests have been developed over the past years. Based on our knowledge on neuroplasticity during sensitive stages, an early intervention in infants with CP is the best strategy [1] (Herskindi, Greisen, \& Nielsen, 2015).

Infant Motor Profile (IMP) is a recent test which evaluates motor behavior of infants aged 3 to 18 months. It can be used for the early detection and the developmental evaluation of high-risk infants in terms of motor disorders, such as $\mathrm{CP}$, or developmental coordination disorders. The evaluation consists of a 15-min video of spontaneous motor behavior in supine, prone, standing, sitting and walking depending on infant's age and functional capacity. In addition, IMP may also evaluate infant ability to reach, grasp and manipulate objects in supine, prone, and sitting position. IMP consists of 80 items and can be applied in infants aged 3 to 18 months. Several studies, on the reliability and concurrent validity between IMP and Alberta Infant Motor Scale (AIMS) and the Touwen Infant Neurological Examination (TINE) have been published. Inter and intra-reliability scores of the instrument were excellent (Spearman's rho 0.90 for both; 95\% CI 0.80 - 0.90 and 0.80 - 1.0 respectively, [5] De Graaf-Peters \& Hadders-Algra, 2006). [6] Heineman, Bos, and Hadders' (2008) study on the IMP validity compared to AIMS and TINE, revealed satisfactory inter and intra-observer reliability. [7] Heinaman et al. (2013), examined IMP inter-observer reliability, but also examined the concurrent validity between IMP and AIMS. IMP reliability scores were satisfactory for all age groups compared with AIMS and typical neurological examination. [8] Hecker et al. (2016) investigated IMP inter and intra-observer reliability with a sample of infants aged 3 to 18 months. Spearman rank correlation showed excellent inter and intra-observer reliability for total IMP $(r=0.80-0.96)$ and performance subscale scores $(r=0.95-0.99)$ 
and weak to strong reliability for the variability subscale $(r=0.30-0.92)$. Weak to fair reliability was obtained for the symmetry subscale (inter: $r=0.20-0.69$ and intra: $r=0.33-0.65$ ).

Thus, the aim of the present study was to examine the reliability of the Greek version of the IMP, with a sample of 3 to 18 -month old infants. The IMP test will not only provide a reliable instrument for relevant practitioners for the evaluation of infant motor behavior and the prediction of future motor disorders, but will also provide a reliable tool for assessing the effectiveness of rehabilitation intervention programs aiming to improving infant motor function.

\section{Method}

\subsection{Participants}

Participants consisted of 20 infants (11 male and 9 female) with mean age of \pm 12.75 months. The participant infants had not been previously diagnosed by neurologist or/and child neurologist. Most infants were premature between 28 and 35 weeks and were hospitalized in the infant intensive care unit until they were 40 weeks old and their weight was approximately $2 \mathrm{~kg}$. The clinicians that were treating them suggested an IMP evaluation.

\subsection{Instrument}

Data were obtained with the use of the following instruments; 1) The Greek version of the IMP. Infant motor assessments were made via video recordings of approximately 15 minutes spontaneous motor behavior when infants were in supine, prone, sitting, standing, and walking depending of their age and functional capacity. In addition, reaching, grasping and object manipulation were assessed in supine and in sitting positions. The evaluation of the 80 IMP items is video-based, and the test is applicable to infants aged 3 to 18 months; 2) For the infant video recordings, a digital camcorder (Nikon 5300) was used.

\subsection{IMP Adaptation Procedure}

First, bilingual experts in paediatric physiotherapy translated the English version of the IMP into Greek, and then two independent bilingual interpreters, also experts in the domain of paediatric physiotherapy, translated the same instrument back into English. The original English version was then compared with the back-translated version and errors and discrepancies were identified. The back-translation comparison process was repeated until all discrepancies were eliminated. The final version exhibited no contradictions with the original English version of the measures when back-translated.

\subsection{Data Analysis}

To examine the reliability of the IMP translated into Greek, intra-rater and inter-rater reliability scores were computed via intra-class correlation coefficients (ICC), using two-way random model, with absolute agreement. Poor ICC values 
are considered scores below 0.50 , whereas values from 0.50 to 0.75 are considered moderate and above 0.75 are considered as good [9] (Portney \& Watkins, 2009). The significance of the results was determined by a $95 \%$ confidence interval (CI) using SPSS v.22.

\section{Results}

Results reveal moderate to excellent agreement for all IMP subscales and sample ages. As for the pilot testing of the Greek version of the IMP, results (Table 1) showed moderate to excellent agreement for all subscales except Variability which resulted in poor agreement.

As for the main study of the Greek version of the IMP (Table 2 \& Table 3), results showed moderate to excellent agreement for all subscales and sample ages. As for the intra-observer agreement scores (Table 4), results were moderate to excellent for both observers.

\section{Discussion}

In the present study, we examined the reliability of the Greek version of the IMP test, using a sample of infants aged 3 to 18 months. Our aim was to provide practitioners with a reliable instrument for the evaluation of infant motor behavior and the prediction of future motor disorders, but also to provide a reliable tool for assessing the effectiveness of rehabilitation intervention programs aiming at improving infant motor function. Results showed no significant differences between observers suggesting that the Greek version of IMP has strong reliability. In particular, results revealed a strong inter-agreement score in total IMP, performance, variation, symmetry, adaptability, and fluency subscale scores. Regarding 12 to 18 months old infants, results showed strong reliability, with ICC scores ranging from 0.785 to 0.961 , while in ages 3 to 12 months, ICC scores also showed a robust agreement between raters ranging from 0.805 to 0.970 . These results are in line with ([6], Heineman, Bos \& Hadders (2008); [10] Heineman, Bos \& Hadders-Algra (2011)), where IMP ability to detect pathologies in infants was highly significant $(p<0.001)$, particularly in the

Table 1. Pilot study ICC scores for the Greek version of the IMP for all subscales and sample ages.

\begin{tabular}{lcc}
\hline \multicolumn{1}{c}{ Variable } & $\mathbf{1 8}$ months $(\mathbf{n}=\mathbf{4})$ & $\mathbf{1 6}$ months $(\mathbf{n}=1)$ \\
\hline 1) Total IMP & $0.972[0.79,0.97]$ & $0.937[0.56,0.91]$ \\
2) Performance & $0.998[0.92,0.98]$ & $0.999[0.98,0.99]$ \\
3) Variation & $0.865[0.12,0.94]$ & $0.218[-0.56,0.61]$ \\
4) Symmetry & $0.999[0.98,0.99]$ & $1[1.00,1.00]$ \\
5) Adaptability & $0.999[0.99,0.99]$ & $1[1.00,1.00]$ \\
6) Fluency & $999[0.98,0.99]$ & $1[1.00,1.00]$ \\
\hline
\end{tabular}

Note: Figures in brackets denote $95 \%$ confidence interval. 
Table 2. Main study ICC scores for the Greek version of the IMP for all subscales, ages 12 to 18 months.

\begin{tabular}{lcccccc}
\hline Variables & $\begin{array}{c}18 \text { months } \\
(\mathbf{n}=6)\end{array}$ & $\begin{array}{c}17 \text { months } \\
(\mathbf{n}=2)\end{array}$ & $\begin{array}{c}16 \text { months } \\
(\mathbf{n}=1)\end{array}$ & $\begin{array}{c}15 \text { months } \\
(\mathbf{n}=2)\end{array}$ & $\begin{array}{c}13 \text { months } \\
(\mathbf{n}=1)\end{array}$ & $\begin{array}{c}12 \text { months } \\
(\mathbf{n}=1)\end{array}$ \\
\hline \multirow{2}{*}{ 1) Total IMP } & 0.785 & 0.839 & 0.936 & 0.909 & 0.939 & 0.961 \\
& {$[0.54,0.99]$} & {$[0.75,0.99]$} & {$[0.82,0.98]$} & {$[0.74,0.99]$} & {$[0.75,0.93]$} & {$[0.85,0.96]$} \\
2) Performance & 0.892 & 0.949 & 0.977 & 0.881 & 0.874 & 0.971 \\
& {$[0.81,0.94]$} & {$[0.73,0.97]$} & {$[0.97,0.99]$} & {$[0.46,0.94]$} & {$[0.54,0.94]$} & {$[0.87,0.98]$} \\
3) Variation & 0.713 & 0.504 & 0.642 & 0.854 & 0.963 & 0.940 \\
& {$[0.51,0.85]$} & {$[0.09,0.75]$} & {$[0.19,0.84]$} & {$[0.73,0.92]$} & {$[0.91,0.99]$} & {$[0.82,0.99]$} \\
4) Symmetry & 0.986 & 0.756 & 0.999 & 0.965 & 0.972 & 0.975 \\
& {$[0.83,0.99]$} & {$[0.22,0.95]$} & {$[0.98,0.99]$} & {$[0.71,0.99]$} & {$[0.81,0.99]$} & {$[0.91,0.99]$} \\
5) Adaptability & 0.533 & 0.999 & 0.999 & 0.907 & 0.888 & 0.921 \\
& {$[0.09,0.81]$} & {$[0.98,0.99]$} & {$[0.98,0.99]$} & {$[0.49,0.96]$} & {$[0.51,0.96]$} & {$[0.63,0.97]$} \\
6) Fluency & 0.801 & 0.989 & 0.999 & 0.942 & 0.999 & 0.999 \\
& {$[0.48,0.96]$} & {$[0.35,0.94]$} & {$[0.98,0.99]$} & {$[0.53,0.98]$} & {$[0.98,0.99]$} & {$[0.98,0.99]$} \\
\hline
\end{tabular}

Note: Figures in brackets denote $95 \%$ confidence interval.

Table 3. Main study ICC scores for the Greek version of the IMP for all subscales, ages 8.5 to 3 months.

\begin{tabular}{lccccc}
\hline Variables & $\begin{array}{c}\mathbf{8 0 . 5} \text { months } \\
(\mathbf{n}=\mathbf{3})\end{array}$ & $\begin{array}{c}\mathbf{5 0 . 5} \text { months } \\
(\mathbf{n}=1)\end{array}$ & $\begin{array}{c}\mathbf{4 0 . 5} \text { months } \\
(\mathbf{n}=\mathbf{1})\end{array}$ & $\begin{array}{c}\mathbf{4} \text { months } \\
(\mathbf{n}=1)\end{array}$ & $\begin{array}{c}\text { 3 months } \\
(\mathbf{n}=1)\end{array}$ \\
\hline 1) Total IMP & 0.917 & 0.959 & 0.970 & 0.843 & 0.805 \\
& {$[0.45,0.98]$} & {$[0.84,0.95]$} & {$[0.84,0.96]$} & {$[0.88,0.93]$} & {$[0.50,0.89]$} \\
2) Performance & 0.915 & 0.993 & 0.981 & 0.945 & 0.617 \\
& {$[0.46,0.96]$} & {$[0.98,0.99]$} & {$[0.91,0.99]$} & {$[0.87,0.98]$} & {$[0.29,0.89]$} \\
3) Variation & 0.908 & 0.889 & 0.895 & 0.812 & 0.869 \\
& {$[0.43,0.96]$} & {$[0.76,0.97]$} & {$[0.61,0.91]$} & {$[0.62,0.91]$} & {$[0.73,0.96]$} \\
4) Symmetry & 0.897 & 0.967 & 0.988 & 0.972 & 0.892 \\
& {$[0.50,0.99]$} & {$[0.75,0.99]$} & {$[0.95,0.99]$} & {$[0.81,0.99]$} & {$[0.42,0.97]$} \\
5) Adaptability & 0.899 & 0.949 & 0.999 & 0.864 & 0.999 \\
& {$[36,0.96]$} & {$[0.74,0.98]$} & {$[0.96,0.99]$} & {$[0.43,0.95]$} & {$[0.99,0.98]$} \\
6) Fluency & 0.969 & 0.999 & 0.999 & 0.936 & 0.651 \\
& {$[0.52,0.97]$} & {$[0.98,0.99]$} & {$[0.98,0.99]$} & {$[0.51,0.98]$} & {$[0.07,0.91]$} \\
\hline
\end{tabular}

Note: Figures in brackets denote $95 \%$ confidence interval.

variation and performance subscales, as in the present study. Furthermore, [11] Hielkema et al. (2011), found that in all ages, AIMS scores correlated poorly with total IMP scores (Spearman's $q 0.36$ - 0.55), but with the IMP Performance subscale they correlated moderate to high (Spearman's $q 0.47-0.84$ ) which contradicts present study as total IMP agreement scores were excellent (ICC $=0.785$ - 0.970). Finally, the results of the present study are in line with [8] Hecker et al. (2016) study, as Spearman's rank correlation results showed strong inter and intra-rater agreement in total IMP $(r=0.80-0.96)$ and performance subscale and fair to strong agreement in variability subscale. Weak correlations were reported for both inter and intra-observer agreement symmetry. 
Table 4. Intra-observer ICC scores for all IMP subscales and ages.

\begin{tabular}{lcccc}
\hline \multirow{2}{*}{ Variables } & \multicolumn{2}{c}{ Observer A } & \multicolumn{2}{c}{ Observer B } \\
\cline { 2 - 5 } & $\begin{array}{c}18 \text { months } \\
(\mathbf{n}=4)\end{array}$ & $\begin{array}{c}16 \text { months } \\
(\mathbf{n}=1)\end{array}$ & $\begin{array}{c}\mathbf{1 8} \text { months } \\
(\mathbf{n}=\mathbf{4})\end{array}$ & $\begin{array}{c}\mathbf{1 6} \text { months } \\
(\mathbf{n}=1)\end{array}$ \\
\hline \multirow{2}{*}{ 1) Total IMP } & 0.951 & 0.984 & 0.932 & 0.705 \\
& {$[0.83,0.99]$} & {$[0.85,0.99]$} & {$[0.41,0.99]$} & {$[0.43,0.99]$} \\
2) Performance & 0.989 & 0.997 & 0.935 & 0.994 \\
& {$[0.96,0.99]$} & {$[0.89,0.99]$} & {$[0.89,0.96]$} & {$[0.86,0.97]$} \\
3) Variation & 0.931 & 0.985 & 0.929 & 0.973 \\
& {$[0.88,0.96]$} & {$[0.96,0.99]$} & {$[0.88,0.96]$} & {$[0.94,0.98]$} \\
4) Symmetry & 0.910 & 0.960 & 0.912 & 0.956 \\
& {$[0.79,0.97]$} & {$[0.85,0.98]$} & {$[0.81,0.97]$} & {$[0.84,0.98]$} \\
5) Adaptability & 0.924 & 0.983 & 0.924 & 0.958 \\
& {$[0.83,0.97]$} & {$[0.94,0.99]$} & {$[0.85,0.96]$} & {$[0.88,0.98]$} \\
6) Fluency & 0.999 & 999 & 961 & 0.600 \\
& {$[0.88,0.99]$} & {$[0.98,0.99]$} & {$[0.41,0.98]$} & {$[0.43,0.91]$} \\
\hline
\end{tabular}

Note: Figures in brackets denote $95 \%$ confidence intervals.

\section{Conclusion}

Overall, the results of the present research provided considerable evidence suggesting that the Greek version of IMP test is reliable and can be used to detect kinetic disorders in infants aged 3 to 18 months.

\section{References}

[1] Herskindi, A., Greisen, G. and Nielsen, J.B. (2015) Early Identification and Intervention in Cerebral Palsy. Developmental Medicine \& Child Neurology, 57, 29-36. https://doi.org/10.1111/dmcn.12531

[2] Schlapbach, L.J., Aebischer, M., Adams, M., Natalucci, G. and Bonhoef, F.J. (2011) Impact of Sepsis on Neurodevelopmental Outcome in a Swiss National Cohort of Extremely Premature Infants. Pediatrics, 128, 348-357. https://doi.org/10.1542/peds.2010-3338

[3] Koman, L.A., Smith, B.P. and Shilt, J.S. (2004) Cerebral Palsy. Lancet, 363, 1619-1631.

[4] Liu, J.-M., Li, Z., Lin, Q., Zhao, P., Zhao, F.-L. and Hong, S.-X. (2000) Cerebral Palsy and Multiple Births in China. Epidemiology, 29, 292-299.

[5] De Graaf-Peters, V.B. and Hadders-Algra, M. (2006) Ontogeny of the Human Central Nervous System: What Is Happening? When? Early Human Development, 82, 257-266. https://doi.org/10.1016/j.earlhumdev.2005.10.013

[6] Heineman K.R. and Hadders-Algra, M. (2008) Evaluation of Neuromotor Function in Infancy-A Systematic Review of Available Methods. Journal of Developmental Behavior, Pediatric, 29, 315-323. https://doi.org/10.1097/DBP.0b013e318182a4ea

[7] Heineman, K.R., Middelburg, K.J., Bos, A.F., Eidhof, L., La Bastide, S. and Van Den Heuvel, E.R. (2013) Reliability and Concurrent Validity of the Infant Motor Profile. Developmental Medicine \& Child Neurology, 55, 539-545. https://doi.org/10.1111/dmcn.12100

[8] Hecker, E.P.T., Baer, G.D., Stark, C.P.T., Herkenrath, P. and Hadders-Algra, M. 
(2016) Inter- and Intrarater Reliability of the Infant Motor Profile in 3- to 18-Month-Old Infants. Pediatric Physical Therapy, 28, 217-222.

https://doi.org/10.1097/PEP.0000000000000244

[9] Portney, L.G. and Watkins, M.P. (2009) Foundations of Clinical Research: Applications to Practice. Pearson/Prentice Hall, Upper Saddle River, NJ.

[10] Heineman, K.R., Bos, A.F. and Hadders-Algra, M. (2011) Infant Motor Profile and Cerebral Palsy: Promising Associations. Developmental Medicine \& Child Neurology, 53, 40-45. https://doi.org/10.1111/j.1469-8749.2011.04063.x

[11] Hielkema, T., Blauw-Hosper, C.H., Dirk, T., Drijver-Messelink, M., Bos, A.F. and Hadders-Algra, M(2011) Does Physiotherapeutic Intervention Affect Motor Outcome in High-Risk Infants? An Approach Combining a Randomized Controlled Trial and Process Evaluation. Developmental Medicine \& Child Neurology, 53, 8-15. https://doi.org/10.1111/j.1469-8749.2010.03876.x 